\title{
Isolated Trochlear Nerve Palsy in Tolosa-Hunt Syndrome
}

\author{
Hiromasa Tsuda, Mayumi Hisada, Kozue Tanaka, Yoshiharu Miura and Shuji Kishida
}

\begin{abstract}
A 67-year-old Japanese woman without contributory medical history developed acute onset of left-sided trochlear nerve palsy (TNP) with persistent and severe periorbital pain. There were no other neurological abnormalities. Funduscopic findings were normal. Cranial and orbital magnetic resonance (MR) imaging, and cranial MR angiography demonstrated no abnormalities. By administration of prednisolone $40 \mathrm{mg} / \mathrm{day}$ from the day after onset, periorbital pain was resolved within 24 hours, and TNP within 5 days. Thereafter, prednisolone was gradually tapered off. She remained asymptomatic under no medication. In the English language literature, this is the first reported case of Tolosa-Hunt syndrome presenting with isolated TNP.
\end{abstract}

Key words: cavernous sinus, cranial fourth nerve, diplopia, painful ophthalmoplegia, prednisolone

(Intern Med 51: 1591-1593, 2012)

(DOI: 10.2169/internalmedicine.51.7349)

\section{Introduction}

Tolosa-Hunt syndrome (THS) is characterized by unilateral periorbital or hemicranial pain accompanied by ipsilateral ocular motor nerve palsies, oculosympathetic impairment, and sensory disturbance in the distribution of the ophthalmic nerve and occasionally the maxillary nerve, and its precise etiology remains unclear (1-4). However, the underlying pathophysiological mechanism has been proven to consist of a granulomatous inflammatory process in the cavernous sinus and/or superior orbital fissure $(2,3)$, which is often demonstrated by cranial magnetic resonance (MR) imaging $(3,4)$. Regarding ocular motor palsy in THS, total ophthalmoplegia, isolated oculomotor nerve palsy, and isolated abducens nerve palsy are commonly observed (1-3). However, in the English language literature, to date there has been no reported case of THS with isolated trochlear nerve palsy (TNP). Here, we describe a case of unilateral TNP with periorbital pain as the sole manifestation of THS.

\section{Case Report}

A 67-year-old Japanese woman without contributory medical history complained of acute onset of diplopia with left-sided periorbital pain in June 2011. The following day, she came to our hospital. She did not complain of any head- ache, despite left-sided severe and persistent periorbital pain. Diplopia was mainly vertical, which was worsened by right downward gaze. She leaned her head slightly to the right side to reduce diplopia. Neither conjunctival injection and chemosis, nor periorbital edema was observed. There was no eruption on her face or head. General examination demonstrated no other abnormalities. Corrected visual acuity was 1.5 in both eyes. Funduscopic examination demonstrated no abnormalities in either eye. The diameter of the pupil was 3 $\mathrm{mm}$ in both eyes in a lighted room. Pupil responses to light and near were prompt in either eye. There was no relative afferent pupillary defect. Palpebral aperture measured $9 \mathrm{~mm}$ bilaterally. Proptosis, lid retraction, lid twitch, enhanced ptosis, and fatiguable ptosis were not observed in either eye. In the primary position, 3 prism diopter of left hypertropia and 2 of esotropia were detected. Bielschowski head tilt test was positive. Maddox rod test demonstrated extorsion of the left eye in the primary position. Intorsion of the left eye was incomplete at right downward gaze. There were no other neurological abnormalities except for left-sided superior oblique muscle paresis (SOMP) (Fig. 1). Complete blood cell count, blood chemistry, and thyroid function were within normal ranges. Electrocardiogram and chest radiograph examination demonstrated normal findings. Cranial and orbital MR imaging as well as cranial MR angiography demonstrated no abnormalities. By administration of oral prednisolone $40 \mathrm{mg} /$ day, left-sided periorbital pain disappeared within 24 hours, 


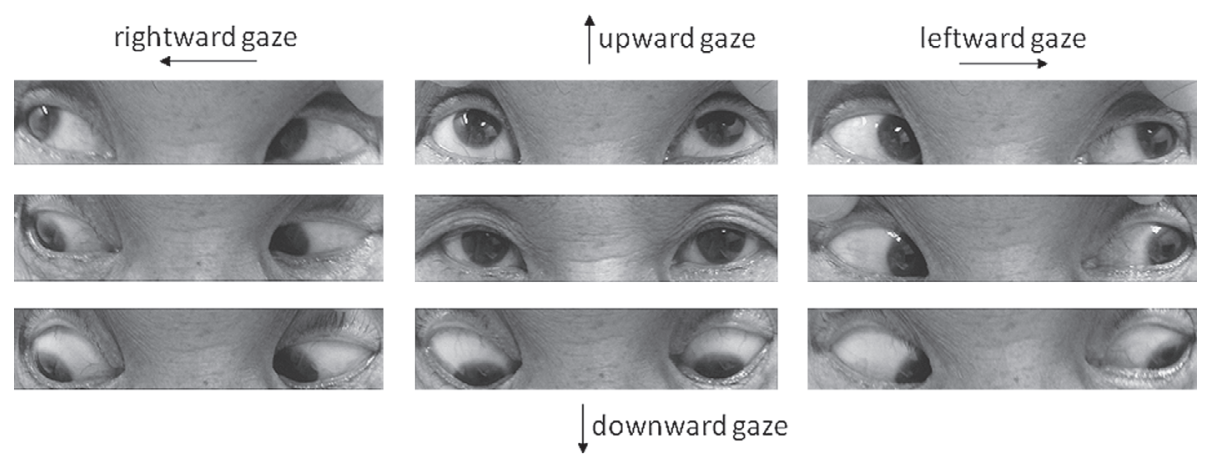

Figure 1. Ocular motor finding. Superior oblique muscle paresis was observed on the left side.

and ophthalmoplegia within 5 days. Thereafter, prednisolone was gradually tapered off. The patient remains asymptomatic under no medication.

\section{Discussion}

The trochlear nerve runs in the vicinity of the oculomotor nerve in the lateral wall of the cavernous sinus (5). Consequently, in cavernous sinus syndrome, the trochlear nerve and oculomotor nerve are usually involved simultaneously, and TNP may be difficult to confirm in the presence of oculomotor nerve palsy and it is probably under represented (6). Therefore, there have been only 4 reported cases of isolated TNP associated with cavernous sinus abnormalities, such as aneurysm $(7,8)$, meningioma (9), and dural carotidcavernous sinus fistula (10).

In Japan, Kashima et al. (1) noted that, of 40 THS cases, isolated oculomotor nerve palsy was observed in 11 cases, isolated abducens nerve palsy in 7, total external ophthalmoplegia in 22, and isolated TNP in 0. Kuroda et al. (11) described the first case of THS with unilateral TNP, but did not discuss its etiology in detail. However, ipsilateral Horner syndrome and an involvement of the ophthalmic nerve were also observed (11). MR imaging was not performed. Although cranial and orbital computed tomography demonstrated no abnormalities, orbital venography demonstrated an occlusion of the superior ophthalmic vein (11). In the English language literature, Kline (2) reported that, of 146 THS cases, oculomotor nerve palsy was observed in 125 cases, abducens nerve palsy in 102, and TNP in 42. However, there has been no reported case of THS with isolated TNP.

In THS, orbital venography may demonstrate that the superior ophthalmic vein is occluded on the affected side, and there may be partial or absent filling of the involved cavernous sinus $(2,12)$. Therefore, orbital venography finding can confirm that the responsible lesion for painful ophthalmoplegia is located within the cavernous sinus. However, in recent years, instead of orbital venography, MR imaging is usually performed for its diagnosis. In the diagnostic criteria for THS in "The International Classification of Headache Disorders, 2nd edition (ICHD-II)" (4), orbital venography is not mentioned. Accordingly, for the definitive diagnosis of THS, we believe that other various causes of painful peripheral ophthalmoplegia should be very carefully excluded.

Regarding various causes of unilateral SOMP, orbital myositis $(13,14)$, thyroid ophthalmopathy (15), trauma (16), surgery (16), cysticercosis (16), peripheral ischemia (16), midbrain stroke (16), congenital (16), multiple sclerosis (17), ophthalmic migraine (18), aneurysm $(7,8)$, cyst (19), neuroborreliosis $(20)$, tumor $(9,21)$, dural carotidcavernous sinus fistula (10), and herpes zoster ophthalmicus (22) have been noted. However, in the present patient, these various causes of unilateral SOMP (7-10, 13-22) could be excluded, based on her clinical course and MR examinations findings. As a result, the present patient was diagnosed as having THS based on the diagnostic criteria in "ICHDII" (4). In the English language literature, this is the first reported case to date of THS presenting with isolated TNP. We considered that oculomotor nerve palsy did not occur and MR imaging demonstrated no abnormalities in the vicinity of the cavernous sinus, because corticosteroid therapy was initiated from only one day after acute onset of ocular symptom. In conclusion, we emphasize that acute onset of unilateral TNP with orbital pain may be an initial manifestation of THS.

The authors state that they have no Conflict of Interest (COI).

\section{References}

1. Kashima $Y$, Nakajima $H$, Tanabe $Y$, Ishikawa $H$, Kitano S. An analysis of 40 cases of the Tolosa-Hunt syndrome. Rinsho Ganka 46: 518-519, 1992 (in Japanese).

2. Kline LB. The Tolosa-Hunt syndrome. Surv Ophthalmol 27: 7995, 1982.

3. Kline LB, Hoyt WF. The Tolosa-Hunt syndrome. J Neurol Neurosurg Psychiatry 71: 577-582, 2001.

4. Colnaghi S, Versino M, Marchioni E, et al. ICHD-II diagnostic criteria for Tolosa-Hunt sundrome in idiopathic inflammatory syndromes of the orbit and/or the cavernous sinus. Cephalalgia 28: 577-584, 2008.

5. Miyazaki Y, Yamamoto I, Shinozuka S, Sato O. Microsurgical anatomy of the cavernous sinus. Neurol Med Chir (Tokyo) 34: 150-163, 1994.

6. Keane JR. Cavernous sinus syndrome. Analysis of 151 cases. Arch Neurol 53: 967-971, 1996.

7. Maurice-Williams RS, Harvey PK. Isolated palsy of the fourth cranial nerve caused by an intracavernous aneurysm. J Neurol Neurosurg Psychiatry 52: 679, 1989. 
8. Arruga J, de Rivas P, Espinet HL, Conesa G. Chronic isolated trochlear nerve palsy produced by intracavernous internal carotid artery aneurysm. Report of a case. J Clin Neuroophthalmol 11: 104-108, 1991.

9. Slavin ML. Isolated trochlear nerve palsy secondary to cavernous sinus meningioma. Am J Ophthalmology 104: 433-434, 1987.

10. Selky AK, Purvin VA. Isolated trochlear nerve palsy secondary to dural carotid-cavernous sinus fistula. J Neuroophthalmol 14: 5254, 1994.

11. Kuroda Y, Kakigi R, Shibasaki H, Oono S. A case of Tolosa-Hunt syndrome presenting trochlear nerve palsy and Horner's syndrome. Rinsho Shinkeigaku 23: 495-500, 1983 (in Japanese, Abstract in English).

12. Muhletaler CA, Gerlock AJ Jr. Orbital venography in painful ophthalmoplegia (Tolosa-Hunt syndrome). AJR Am J Roentgenol 133: 31-34, 1979.

13. Moorman CM, Elston JS. Acute orbital myositis. Eye 9: 96-101, 1995.

14. Kau HC, Kao SC, Peng CH, Hsu WM, Tsai CC. Methylprednizolone pulse therapy in patient with isolated superior oblique myositis. Eye 20: 1106-1109, 2005.

15. Moster ML, Bosley TM, Slavin ML, Rubin SE. Thyroid ophthalmopathy presenting as superior oblique paresis. J Neuroophthal- mol 12: 94-97, 1992.

16. Keane JR. Fourth nerve palsy: historical review and study of 215 patients. Neurology 43: 2439-2443, 1993.

17. Thömke F, Lensch E, Ringel $\mathrm{K}$, Hopf HC. Isolated cranial nerve palsies in multiple sclerosis. J Neurol Neurosurg Psychiatry 63: 682-685, 1997.

18. Lal V, Sahota P, Singh P, Gupta A, Prabhakar S. Ophthalmoplegia with migraine in adults: is it ophthalmoplegic migraine? Headache 49: 838-850, 2009.

19. Tailor R, Mollan SP, Burdon MA. Intracranial dermoid cyst presenting as an isolated fourth nerve palsy. J Neurol 256: 820-821, 2009.

20. Müller D, Neubauer BA, Waltz S, Stephani U. Neuroborreliosis and isolated trochlear palsy. Eur J Pediatr Neurol 2: 275-276, 1998.

21. Tsuda H, Ishikawa $H$, Matsunaga $H$, Asayama K, Saito N. Optic tract syndrome, Horner's syndrome, and trochlear nerve palsy due to suprasellar germinoma. Neuroophthalmology 29: 129-132, 2005.

22. Tsuda $H$, Ito $T$, Yoshioka $M$, Ishihara $N$, Sekine Y. Isolated trochlear nerve palsy in herpes zoster ophthalmicus. Intern Med 46: 535-536, 2006.

(C) 2012 The Japanese Society of Internal Medicine http://www.naika.or.jp/imindex.html 